\title{
PERCEPÇÃO DO CONHECIMENTO SOBRE RESÍDUOS SÓLIDOS DA CONSTRUÇÃO CIVIL POR GRADUANDOS E GRADUADOS EM ENGENHARIA CIVIL
}

\author{
Gabriel Sousa de Freitas ${ }^{1}$ \\ Patricia Bulbovas ${ }^{2}$ \\ Regina de Oliveira Moraes Arruda ${ }^{3}$
}

Resumo: $O$ estudo realizado avaliou o grau de conhecimento referente aos resíduos sólidos da construção civil de estudantes de engenharia civil e profissionais de engenharia civil, durante a sua formação e atuação profissional. Realizou-se uma análise quantitativa com aplicação de um questionário com 15 perguntas referente a resíduos da construção civil, abordando tópicos como: órgãos fiscalizadores, legislação do resíduo da construção civil, descarte, reuso, interesse social e Educação Ambiental divididas em cinco temas. Os resultados obtidos permitiram concluir que ambos os grupos possuem conhecimento a respeito do CONAMA e sua Resolução $n^{\circ}$ 307, também foi constatado que uma parcela dos estudantes de engenharia civil e engenheiros civis não conseguem realizar o descarte de forma correta e não consideram ter um conhecimento suficiente, apesar de terem conhecimento da legislação. Compreendemos que ambos os grupos, apesar de possuírem uma ciência da legislação, não executam o descarte de forma correta por alguns itens, tais como, falta de incentivo fiscal, falta de uma Educação Ambiental, falta de conhecimento sobre o tema e a não existência de um órgão fiscalizador efetivo.

Palavras-chave: Educação Ambiental; Resíduo; Engenheira Civil; Descarte Irregular.

\footnotetext{
1Universidade Guarulhos. E-mail: gsousadefreitas@gmail.com, Link para o Lattes: lattes.cnpq.br/8260948794670954

2 Universidade Guarulhos. E-mail: pbulbovas@hotmail.com.br. Link para o Lattes: lattes.cnpq.br/3482318344407180

3 Universidade Guarulhos. E-mail: rarruda@prof.ung.br Link para o Lattes: lattes.cnpq.br/4727957451446391
} 
Abstract: The study evaluated the degree of knowledge regarding solid waste from civil construction of civil engineering students and civil engineering professionals, during their training and professional performance. A quantitative analysis was carried out with the application of a questionnaire with 15 questions regarding civil construction waste, covering topics such as: inspection agencies, civil construction waste legislation, disposal, reuse, social interest, and environmental education divided into five themes. The results obtained allowed us to conclude that both groups have knowledge about CONAMA and its Resolution $\mathrm{N}^{\circ} 307$. It was also found that a portion of civil engineering students and civil engineers are not able to perform the disposal in a correct way and do not consider that they have enough knowledge, despite their knowledge of the legislation. We understand that both groups, despite being aware of the legislation, do not perform the disposal in a correct way due to some items, such as lack of fiscal incentive, lack of environmental education, lack of knowledge on the subject and the non-existence of an effective enforcement agency.

Keywords: Environmental Education; Waste; Civil Engineering, Irregular Disposal.

\section{Introdução}

Nas últimas décadas, observa-se grande desenvolvimento econômico, crescimento populacional, mudanças tecnológicas e urbanização, que vem sendo acompanhado pela mudança do modo de vida e os processos de produção e consumo da população (GOUVEIA, 2012). Por consequência, os recursos naturais estão sendo utilizados abundantemente para satisfazer as necessidades humanas, sendo necessário que o ser humano reveja seu conceito de desenvolvimento.

Segundo Souza (2015), o setor da construção civil impacta a economia de um país por suas atividades estarem ligadas à geração de renda, tributos e empregos. O setor é um dos maiores indicadores que uma economia está crescendo num país, no entanto, ele é responsável por inúmeros impactos ambientais.

Segundo Paschoalin Filho e Graudenz (2012), o setor da construção civil causa impactos além do extrativismo, possuindo outras formas de impacto ambiental, tais como: poluição atmosférica e sonora, contaminação do solo, geração de resíduos, entre outros. Silva (2003) também afirma que é o setor que mais gera impactos ao meio ambiente, desde a extração de matéria-prima até a geração de resíduos. O setor também é responsável por $20 \%$ a $50 \%$ de tudo que é consumido pela sociedade (MESQUITA, 2012).

Os impactos ambientais causados pela construção civil ocorrem em todo o seu ciclo de atividade. A construção civil envolve várias etapas e possui relação com o meio ambiente no qual está inserida, tais como, supressão vegetal, movimentação do solo na fase de terraplenagem, consumo de recursos naturais para execução dos elementos de concreto, geração de resíduos associados a diversas atividades, até as atividades finais de acabamento (VECHI; GALLARDO; TEIXEIRA, 2016). 
Os resíduos sólidos causam inúmeros problemas na sociedade, desde danos ambientais até danos à saúde. Ulsen et al. (2010) estimam que cerca de $50 \%$ dos resíduos sólidos das cidades brasileiras são oriundos da construção civil.

A Associação Brasileira de Empresas de Limpeza Pública e Resíduos Especiais (ABRELPE), no seu panorama de 2018, afirmou que os serviços de limpeza dos municípios do Brasil coletaram no ano de 2018 cerca de 122.012 toneladas/dia de resíduo da construção civil (RCC) em vias públicas. O gestor da obra é o responsável pelo resíduo, e a quantidade coletada é apenas daquilo que foi coletado nas vias públicas do Brasil (ABRELPE, 2018).

A Resolução do CONAMA n 307/2002 Brasil, 2002 definiu RCD como: os provenientes de construções, reformas, reparos e demolições de obras de construção civil, e os resultantes da preparação e da escavação de terrenos (BRASIL, 2002).

Já a Associação Brasileira de Reciclagem de Resíduos da Construção Civil e Demolição (ABRECON) definiu RCD como: todo resíduo gerado no processo construtivo, de reforma, escavação ou demolição (ABRECON, 2020).

Para uma construção sustentável, é necessário que todas as partes estejam envolvidas, desde os geradores de resíduos até os gestores públicos, para adoção de medidas que mitigam os impactos ambientais provenientes do processo como, por exemplo, a Educação Ambiental (CATUNDA PINTO; SANTOS; CATUNDA, 2015).

A Educação Ambiental é um processo permanente, através do qual o indivíduo e a comunidade tomam consciência em relação ao meio ambiente. Por meio da obtenção de conhecimentos, valores, habilidades e experiências conectadas ao meio ambiente é possível resolver os problemas ambientais (SOUZA; MARQUES JUNIOR, 2001).

De acordo com Sousa et al. (2015) as faculdades de engenharia civil não devem apenas proporcionar aos estudantes disciplinas especificas ligadas ao meio ambiente, mas sim uma abordagem interdisciplinar, tornando-a um pilar na elaboração da consciência ecológica e no incentivo de ações ecológicas de forma correta ao engenheiro civil.

Se a engenharia civil está ligada ao crescimento econômico e aos impactos ambientais causados por ela, a formação de profissionais nessa área deve assegurar que o desenvolvimento econômico não prejudique 0 meio ambiente e a sociedade. Assim, a Educação Ambiental no curso de engenharia civil deveria ser uma ferramenta para auxiliar na formação dos conhecimentos dos danos causados pelo setor.

Segundo Escrivão e Nagano (2014, p 139), 
No cenário atual, as instituições educacionais, em todos os níveis, apresentam um papel importante como instrumento de promoção de valores relacionados ao desenvolvimento sustentável. As universidades têm função da educação profissional e acadêmica e, também, a educação para a cidadania, para a convivência em comunidade, para o social e para o meio ambiente. Elas formam gestores e professores e têm ainda 0 importante papel de fonte geradora de conhecimento através da pesquisa científica, modificando atitudes e comportamentos no sentido de uma consciência ambiental e de uma responsabilidade ética.

Diante da crise ambiental ocorrida ao longo do tempo, faz-se necessário propor algumas ações de conscientização das pessoas sobre a necessidade de proteção dos recursos naturais, tendo a Educação Ambiental como meio importante e alternativo (MARCOTTO; TESSARO; TESSARO, 2014).

Diante do exposto, torna-se importante que sejam realizados estudos que identifiquem o comportamento do profissional de engenharia civil referente ao (RCD), sendo assim, este artigo tem como objetivo avaliar o grau de conhecimento dos alunos de engenharia civil durante a sua formação e dos profissionais de engenharia civil referente aos resíduos sólidos da construção civil.

\section{Material e Método}

Trata-se de um estudo quantitativo, com a aplicação de um questionário feito para avaliar o grau de conhecimento dos estudantes e profissionais de engenharia civil referente aos resíduos sólidos da construção civil. A pesquisa foi submetida ao Comitê de Ética em Pesquisa (CEP), tendo como número do parecer de aprovação o CAE 3.973.025. O período da pesquisa foi de março a setembro de 2020. O público-alvo do estudo foram os estudantes de engenharia civil e os profissionais da engenharia civil. Os participantes do estudo foram aqueles que se enquadram nos seguintes critérios: o participante deveria ser maior de 18 anos, estar matriculado entre o $1^{\circ}$ semestre e $010^{\circ}$ semestre do curso de Engenharia Civil, ou ser profissional formado em Engenharia Civil.

Os estudantes e profissionais de engenharia civil foram convidados para responder o questionário por meio de mensagens eletrônicas. Elas foram enviadas para amigos, colegas de profissão e professores por meio de grupos de redes socais, reunião de negócios e e-mail.

Os pesquisadores também entraram em contato com os profissionais de engenharia civil por meio de reuniões, workshop e redes profissionais (LinkedIn, fóruns, Bebee, Viadeo, entre outros). 
Os participantes da pesquisa responderam ao questionário via internet, e para isso foi utilizada a ferramenta Google Forms. Para avaliar o grau de conhecimento dos participantes foi construído um questionário com 15 perguntas, agrupadas em cinco temas: formação, conhecimento sobre o assunto, conhecimento sobre a Resolução CONMA $n^{\circ} 307$, interesse pelo assunto e conscientização.

O questionário foi enviado por e-mail e/ou WhatsApp para que o participante pudesse responder entre abril de 2020 até setembro de 2020. Desta forma, o método que foi utilizado para o recrutamento dos estudantes de engenharia civil e os profissionais foi a técnica snowball sampling. Nesta técnica, os próprios participantes indicam possíveis outros participantes para realizar a pesquisa, por meio da sua rede de contato. A técnica é utilizada para prospecção de participantes.

Caso qualquer participante interrompesse ou não finalizasse seu questionário, suas respostas não eram computadas, porém seus dados foram armazenados caso o participante retornasse a pesquisa.

Os dados obtidos com o questionário foram armazenados em planilhas para posterior análise. Foram realizadas análises quantitativas dos dados agrupados para os cinco temas (formação, conhecimento sobre o assunto, conhecimento sobre a lei, interesse pelo assunto e conscientização) construindo gráficos, a fim de identificar o grau de conhecimento de alunos e profissionais da engenharia civil referente à formação e destinação dos resíduos sólidos da construção civil.

\section{Resultados e Discussões}

O questionário foi aplicado para estudantes de engenharia civil e engenheiros civis, totalizando 180 participantes, dos quais 125 eram engenheiros civis formados e 55 estudantes de engenharia civil.

O primeiro tema abordou questões referentes à formação do engenheiro civil e do estudante de engenharia civil, a fim de saber se durante a sua formação foi abordado, em algum momento, o assunto RCD.

Primeiramente, foi perguntado ao grupo dos engenheiros civis qual era o tempo de sua formação profissional. A maior parcela dos participantes da pesquisa respondeu de 0 a 5 anos (76\%), seguido por aqueles formados entre 5 e 10 anos (11\%), 10 e 15 anos (9\%) e 20 anos ou mais (4\%). Ao grupo de estudantes de engenharia civil foi perguntado qual semestre do curso eles estavam cursando. $\mathrm{O}$ maior percentual de alunos entrevistados encontrava-se no $10^{\circ}$ semestre $(27 \%)$, seguido pelos alunos do $9^{\circ}$ semestre $(25 \%)$, alunos do $7^{\circ}$ semestre (20\%). Os alunos do $8^{\circ}, 1^{\circ}, 3^{\circ}, 6^{\circ}$ e $5^{\circ}$ semestre corresponderam, respectivamente, a $11 \%, 6 \%, 5 \%, 4 \%$ e $2 \%$ (Figura 1 ). 


\section{Há quanto tempo é formado em engenharia civil ?}

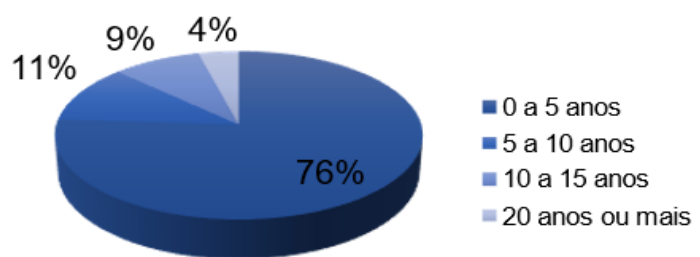

Qual semestre do curso de engenharia civil atualmente você está cursando?

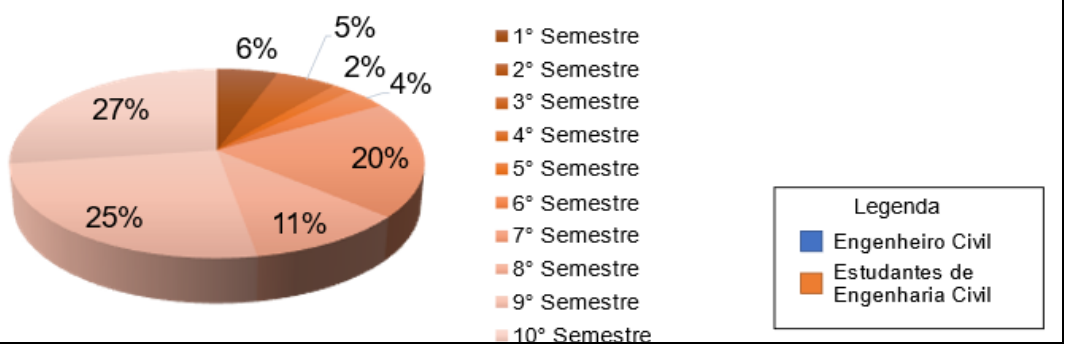

Figura 1: Tempo de formação dos engenheiros civis e semestre que os estudantes de engenharia civil estão cursando.

Outras questões abordadas sobre o tema formação foram referentes ao conhecimento dos participantes da pesquisa sobre o CONAMA e a Resolução CONAMA n 307.

A questão referente ao conhecimento sobre o CONAMA foi abordada devido ele ser um órgão nacional responsável pela preservação do meio ambiente. Os resultados mostraram que $87 \%$ dos engenheiros civis e $75 \%$ dos estudantes de engenharia civil têm ciência do que é o CONAMA (Figura 2).

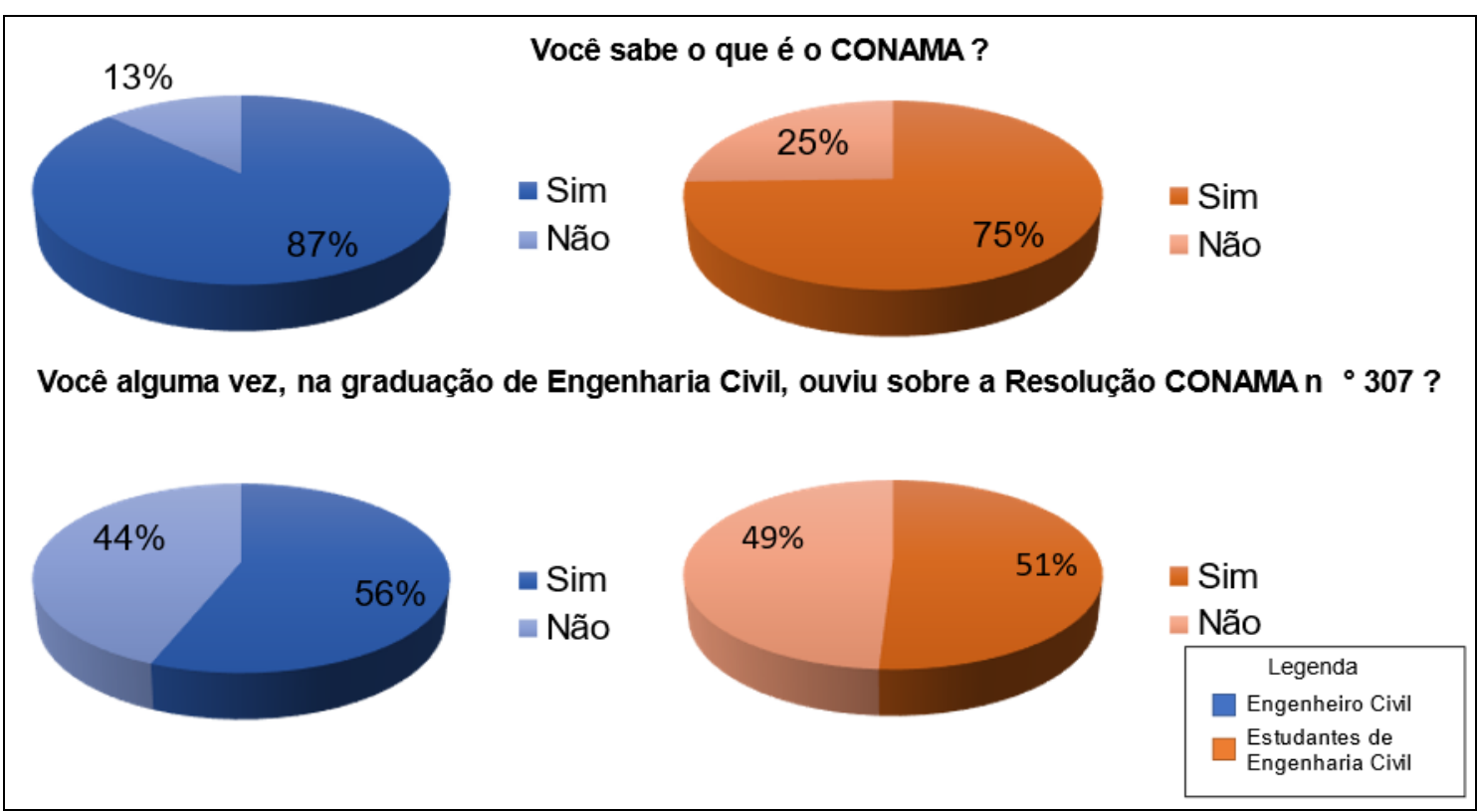

Figura 2: Conhecimento referente ao CONAMA e a Resolução $n^{\circ} 307$. 
Avaliando a questão referente à Resolução CONAMA $n^{\circ} 307$, que estabelece as diretrizes, critérios e procedimentos para a gestão dos resíduos da construção civil, nota-se que $56 \%$ dos engenheiros civis e $51 \%$ dos estudantes de engenharia civil tiveram contato com a Resolução (Figura 2).

O estudo realizado por Aragão et al. (2014), referente à análise do conhecimento dos profissionais da construção civil sobre os resíduos da construção civil e demolição, na cidade de Campo Mourão (PR), mostrou que $80 \%$ dos participantes conheciam as normas referentes ao RCD.

Azevedo, Kipersto, Moraes (2006) consideram que a Resolução CONAMA n $n^{\circ} 307 / 02$ é positiva em relação à gestão dos RDC, pois ela garante um melhor desempenho da construção civil, principalmente quanto à prevenção da geração de resíduos.

Já Tavares et al. (2019), analisaram 8 empresas a fim de identificar a quantidade e a destinação do RCD. Neste estudo, foi identificado que existe a falta de conhecimento do CONAMA e da aplicação da Resolução $n^{\circ} 307$ por parte das empresas, e que $37 \%$ delas mostraram realizar de forma incorreta 0 descarte do resíduo por meio de empresas clandestinas.

O segundo tema abordado foi referente ao conhecimento dos participantes da pesquisa sobre o assunto resíduos sólidos na construção civil. Foram realizadas questões a fim de avaliar o grau de conhecimento sobre os resíduos da construção civil e seu descarte (Figura 3).

Analisando a questão referente ao grau de conhecimento sobre o RCD, observa-se que grande parte dos engenheiros civis e estudantes de engenharia civil consideraram que não possuem conhecimento suficiente sobre o resíduo em questão ( $36 \%$ e $42 \%$, respectivamente), sendo assim, não conseguem realizar o descarte de forma correta (Figura 3).

As respostas para a questão relacionada ao descarte do RCD mostram que $78 \%$ dos engenheiros civis não consideraram ter um conhecimento suficiente sobre o descarte do resíduo. Nota-se que as respostas dos estudantes de engenharia civil apresentaram um padrão de resultados similar ao dos engenheiros civis formados, onde $84 \%$ consideraram não ter um conhecimento suficiente sobre o tema (Figura 3). Esse resultado difere do que Aragão et al. (2014) encontraram em estudo realizado na cidade de Campo Mourão (PR), onde cerca de $60 \%$ dos participantes da pesquisa afirmaram que executam de forma correta o descarte do resíduo, e 10\% disseram que, às vezes, o realiza de forma correta.

Analisando os resultados obtidos a respeito do grau de conhecimento sobre o RCD e seu descarte, observa-se que existe uma relação entre o déficit de conhecimento sobre o resíduo e o seu descarte, afetando diretamente sua destinação. 


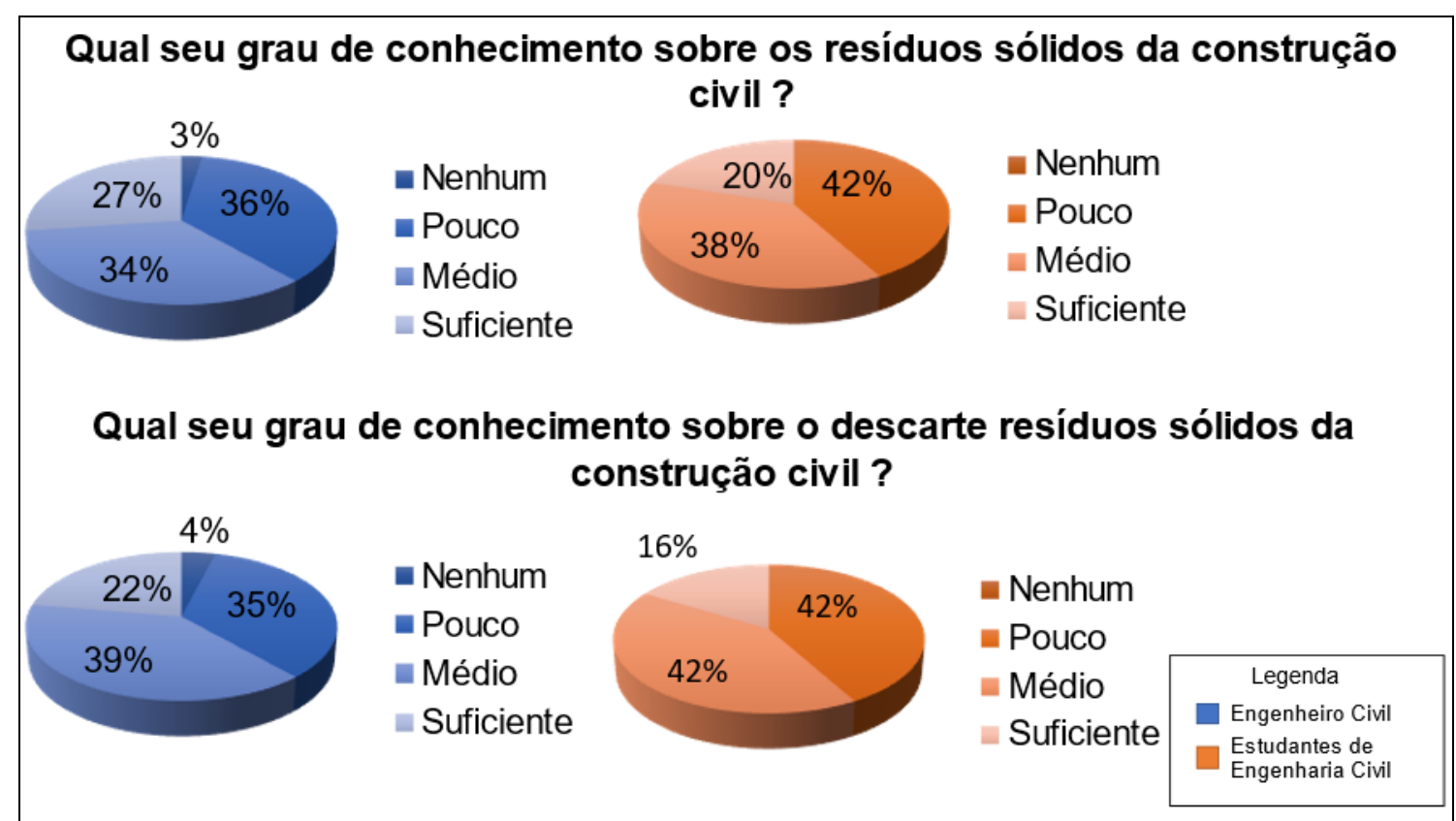

Figura 3: Grau de conhecimento sobre o resíduo da construção civil e seu descarte.

O terceiro tema abordado no questionário buscou avaliar se os participantes tinham algum conhecimento sobre a legislação que regula o resíduo da construção civil. Para tanto, foram apresentadas questões sobre o responsável pela classificação do RCD, sua definição por classe, a realização da separação do resíduo e a sua fiscalização.

Ao analisar as respostas sobre o responsável pela classificação dos resíduos da construção civil, observa-se que, tanto os engenheiros civis como os estudantes de engenharia civil, em sua maior parcela, tem conhecimento de quem é o responsável pela classificação do resíduo (59\% e 55\%, respectivamente) (Figura 4).

A Resolução $n^{\circ}$ 307/2002 Brasil, 2002, determinou que os geradores de RCD são pessoas físicas ou jurídicas, públicas ou privadas, responsáveis por atividades ou empreendimentos que gerem os resíduos definidos nesta Resolução (BRASIL, 2002), ou seja, o engenheiro civil se torna um dos responsáveis pela gestão do resíduo.

O estudo realizado por Schneider e Philippi Jr. (2004) mostrou que os geradores de RCD são indiferentes em relação à sua responsabilidade sobre o RCD, que não possuem informação e/ou apenas se interessam pelo menor custo da caçamba, contratando empresas ilegais que causam o descarte do resíduo de forma irregular.

Nota-se que o engenheiro civil e o estudante de engenharia civil sabem quem é o responsável pela gestão do resíduo gerado na obra (59\% e 55\%, respectivamente; Figura 4), e ambos sabem, em sua maioria, quais são as definições por classe do RCD (72\% e 60\%, respectivamente; Figura 4). 


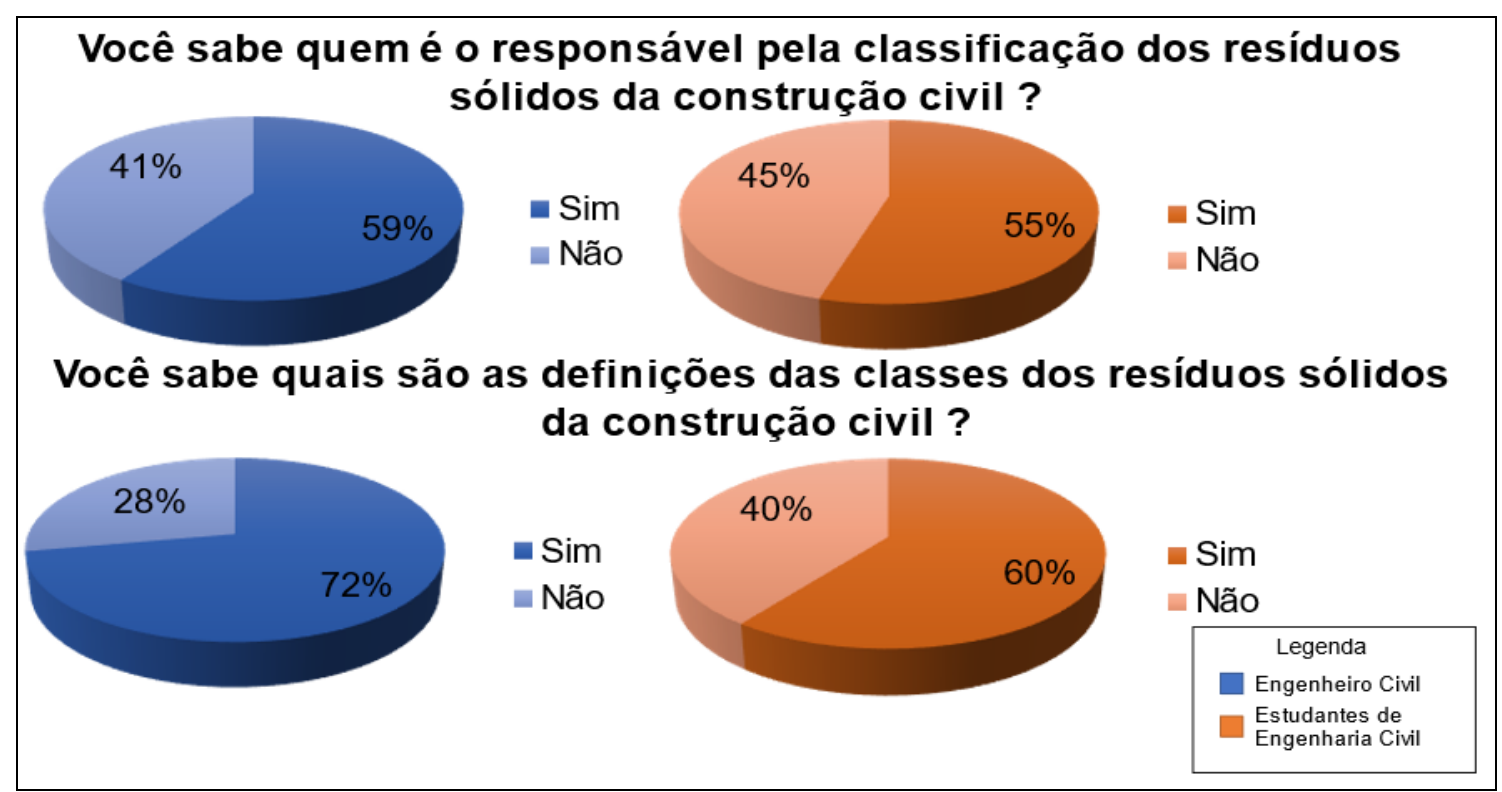

Figura 4: Conhecimento sobre a responsabilidade do RCD e suas definições.

Freitas e Bulbovas (2020), verificaram que, apesar do engenheiro civil ser um dos responsáveis pela gestão do resíduo, ele apresenta falta de uma Educação Ambiental referente ao tema apesar de possuir conhecimento técnico.

As respostas para a questão que avaliou o conhecimento sobre a separação dos resíduos da construção civil, mostraram que uma pequena parcela dos engenheiros civis e estudantes de engenharia civil consideraram ter um conhecimento suficiente sobre o assunto $(16 \%$ e $24 \%$, respectivamente), entretanto o restante dos participantes considerou ter nenhum ou médio conhecimento, sendo que grande parcela dos participantes conhecem as definições, porém não executam a separação (Figura 5).

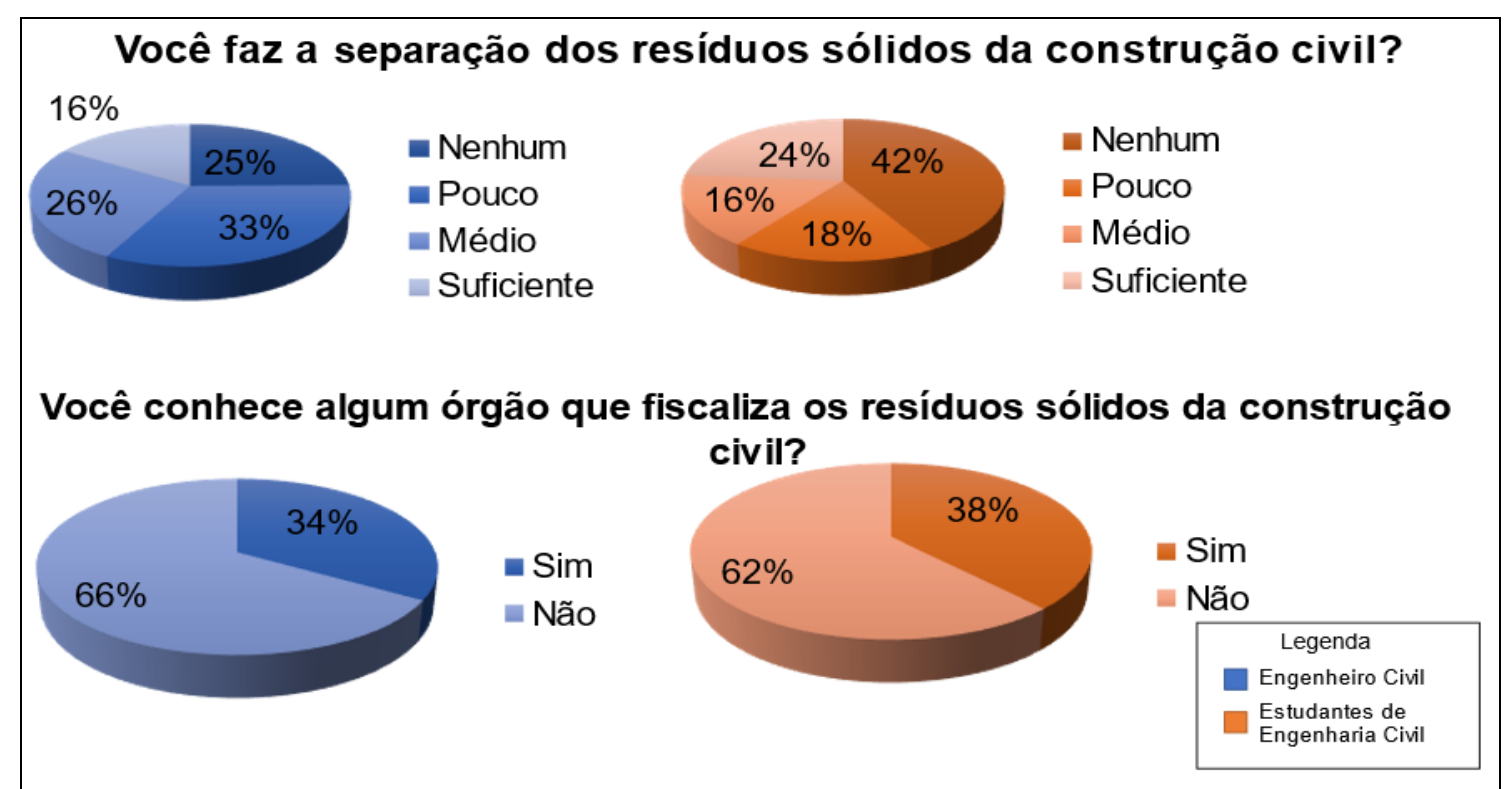

Figura 5: Conhecimento sobre a separação e fiscalização do RCD.

Revbea, São Paulo, V. 16, № 4: 305-319, 2021. 
Avaliando a questão sobre a fiscalização do RCD, os participantes chegaram a resultados semelhantes, onde $66 \%$ dos engenheiros e $62 \%$ dos estudantes de engenharia civil afirmaram não conhecer nenhum órgão fiscalizador.

No quarto tema, buscou-se avaliar a conscientização ambiental do participante da pesquisa, perguntando se ele pensava que o descarte de forma incorreta causaria impacto ambiental, se algum incentivo fiscal ajudaria na reciclagem do $R C D$ e se ele reusaria o material proveniente da construção civil (Figura 6).

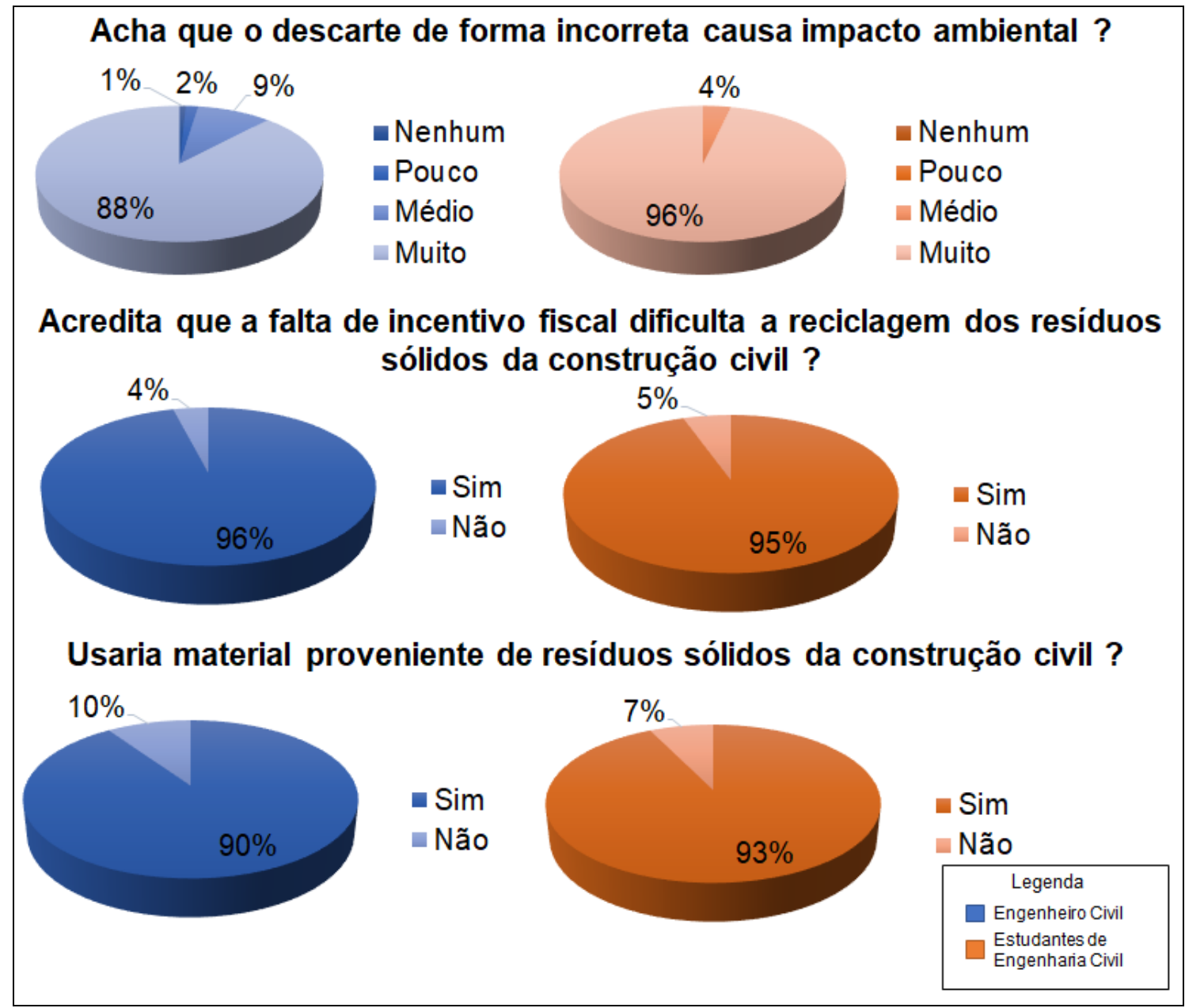

Figura 6: Conscientização sobre o descarte, incentivo fiscal e reciclagem do RCD.

Os resultados mostraram que tanto engenheiros civis como estudantes de engenharia civil acreditam que o descarte de forma incorreta causa algum impacto ambiental, que a falta de um incentivo fiscal dificulta a reciclagem do RCD e que usariam um material proveniente do RCD.

Deve-se ainda considerar que essa questão dos resíduos sólidos da 
processo, como o treinamento da mão-de-obra envolvida, a fim de estimular a redução do desperdício na obra (AZEVEDO, KIPERSTO, MORAES, 2006).

Cerca de $88 \%$ dos engenheiros civis pensam que o descarte de maneira incorreta afeta muito o meio ambiente e $96 \%$ dos estudantes de engenharia civil também têm esse pensamento. Na questão sobre o incentivo fiscal, os resultados são parecidos, $96 \%$ dos engenheiros civis e $95 \%$ dos estudantes de engenharia civil acham que se houvesse um incentivo fiscal haveria mais reciclagem do resíduo. Também os engenheiros civis e estudantes de engenharia civil, na questão sobre o uso de um material proveniente do RCD, tiveram um resultado semelhante, aproximadamente $90 \%$ dos engenheiros civis e $93 \%$ dos estudantes de engenharia civil usariam um material proveniente do RCD (Figura 6). Entretanto, Aragão et al. (2014), em seu estudo, verificaram que $40 \%$ aceitariam o reuso de um material procedente de RCD.

O uso de materiais reciclados pode ajudar a preservar os recursos naturais e minimizar os impactos ambientais causados pela construção civil, lembrando que os agregados naturais são recursos finitos e esgotáveis (TAUMATURGO et al., 2019).

Silva et al. (2019) afirmaram que o engenheiro civil tem a capacidade técnica de reutilizar o resíduo para o desenvolvimento de uma construção mais sustentável, para diminuir o desperdício de material.

O último tema abordado buscou conhecer o interesse dos participantes pelo assunto, se os engenheiros civis e os estudantes de engenharia civil tinham necessidade de ter mais conhecimento sobre o RCD. Os resultados obtidos, por meio do questionário, mostraram que $94 \%$ dos engenheiros civis sentem necessidade de conhecer mais sobre o assunto e $98 \%$ dos estudantes de engenharia civil também sentem necessidade de saber mais sobre o tema (Figura 7).

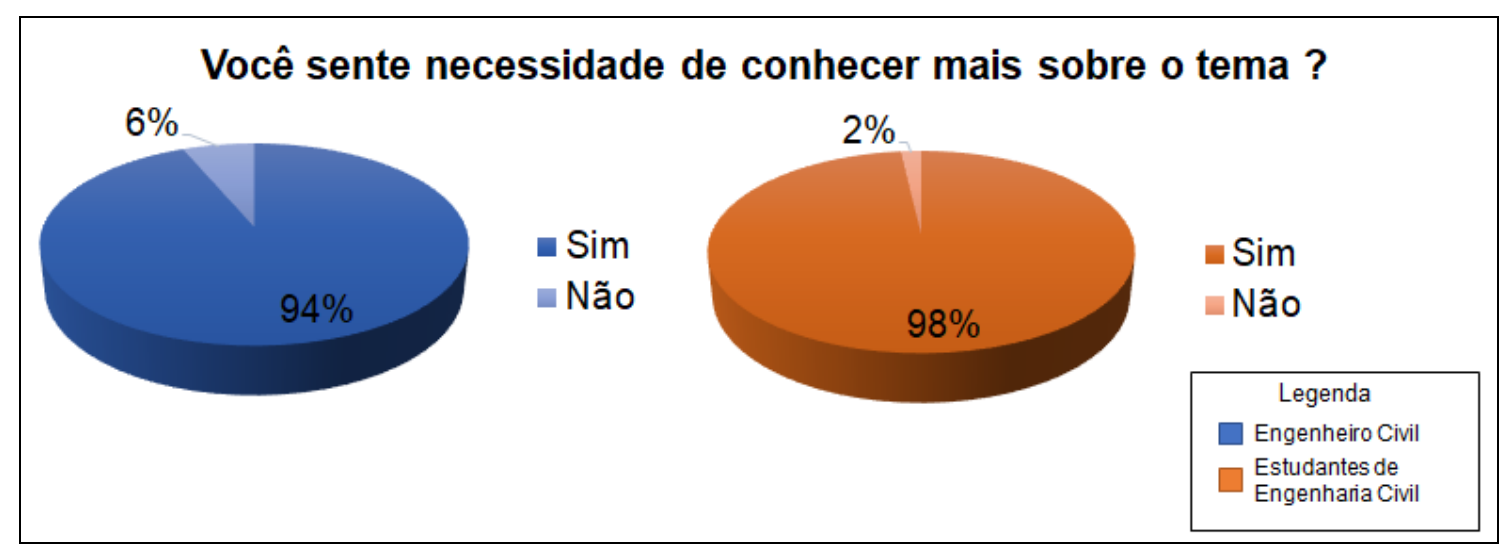

Figura 7: Conscientização. 
De um modo geral, os engenheiros civis e os profissionais de engenharia civil demostraram possuir um interesse sobre o tema RCD, conhecimento sobre a legislação ligada a ele, ter uma consciência ambiental e ter obtido conhecimento sobre o tema durante a formação, no entanto, não possuem uma Educação Ambiental direcionada ao tema.

Apesar dos engenheiros civis e estudantes de engenharia civil terem todas as informações necessárias para que o descarte ocorra de forma correta, o descarte do RCD não está acontecendo pela falta de fiscalização e a falta de Educação Ambiental. Também, deve-se considerar a falta de interesse do gerador do resíduo.

Outros estudos apontaram resultados semelhantes. Da Silva e Fernandes (2012) acreditam que a população de Uberaba (MG) não possui uma Educação Ambiental referente à gestão do RCD. Já Paschoalin Filho e Graudenz (2012) afirmam que se faz necessário uma conscientização referente ao RCD dos envolvidos na construção civil.

Os autores citados acima, em seu estudo, relataram que a maior parte do RCD descartado de forma irregular é proveniente de pequenas construções e reformas, e que a sua destinação é realizada por empresas irregulares.

\section{Conclusões}

O presente artigo teve como objetivo avaliar o grau de conhecimento dos alunos de engenharia civil durante a sua formação e dos profissionais de engenharia civil referente aos resíduos sólidos da construção civil. A pesquisa teve 180 participantes, dois quais 55 eram estudantes de engenharia civil e 125 engenheiros civis formados. Os resultados obtidos permitiram concluir que a maioria dos estudantes de engenharia civil, juntamente com os engenheiros civis, possuem conhecimento a respeito do CONAMA e sua Resolução n 307.

Foi constatado que uma parcela de ambos os grupos avaliados não consegue realizar um descarte de forma correta e que não consideram ter um conhecimento suficiente sobre o tema. Apesar do engenheiro civil e do estudante de engenharia civil terem o conhecimento da Resolução $n^{\circ} 307$, ambos não possuem conhecimento técnico para realizar o descarte do resíduo.

Outro ponto analisado foi a respeito da ciência da geração de resíduos dentro do canteiro de obras, os engenheiros civis e os estudantes de engenharia civil, em sua maioria, sabem quem é o responsável pela classificação dos resíduos e o responsável pelo seu gerenciamento. Foi possível notar que os participantes da pesquisa conhecem sobre a classificação do resíduo, porém não o gerenciam de acordo com esse conhecimento.

Nenhum dos grupos, em sua maioria, conhece algum órgão fiscalizador 
impacto ambiental, que um incentivo fiscal ajudaria no reuso do material e que usariam algum material proveniente dos resíduos sólidos da construção civil.

Compreendemos que ambos os grupos, apesar de terem um conhecimento da legislação, não realizam o descarte de forma correta por alguns motivos, tais como, falta de incentivo fiscal, falta de uma Educação Ambiental, falta de conhecimento sobre o tema e a não existência de um órgão fiscalizador efetivo.

Ações de conscientização e sensibilização a respeito do tema podem levar os grupos estudados a uma atitude correta em relação a destinação dos resíduos sólidos da construção civil, pois tal atitude não deve ficar condicionada apenas a existência de fiscalização.

\section{Referências}

ABRECON - Associação Brasileira para Reciclagem de Resíduos da Construção Civil e Demolição. 0 que é entulho. Disponível em: $<$ https://abrecon.org.br/>. Acesso em 18 de nov de 2020.

ABRELPE, Associação Brasileira de Empresas de Limpeza Pública e Resíduos Especiais. Panorama dos resíduos sólidos no Brasil, 2018. Disponivel em:< https://abrelpe.org.br/panorama/>. Acesso em 30 de jan de 2021.

ARAGÃO, F. V. et al. Análise do conhecimento dos profissionais da construção civil sobre os resíduos de construção civil e demolição na cidade de Campo Mourão-PR. REGET-Revista Eletrônica em Gestão, Educação e Tecnologia Ambiental, Santa Maria, v. 18, n. 4, p. 1326-1333, 2014.

AZEVEDO, G. O. D.; KIPERSTOK, A.; MORAES, L. R. S. Resíduos da construção civil em Salvador: os caminhos para uma gestão sustentável. Eng. Sanit. Ambient., Rio de Janeiro , v. 11, n. 1, p. 65-72, Mar. 2006.

BRASIL. Resolução CONAMA n. 307 - Estabelece diretrizes, critérios e procedimentos para a gestão dos resíduos da construção civil. Diário Oficial da República Federativa do Brasil de 17 de julho de 2002. Disponível em: http://www2.mma.gov.br/port/conama/legiabre.cfm?codlegi=307. Acesso em 29 de jan de 2021.

CATUNDA PINTO, C. H.; SANTOS, A. L.; CATUNDA, A. C. M. M.. Percepção da legislação ambiental, gestão e destinação final dos RCD - resíduos da construção e demolição: um estudo de caso em Parnamirim/RN/Brasil. HOLOS, [S.I.], v. 2, p. 33-49, abr. 2015.

FREITAS, G. S., BULBOVAS, P. Os avanços da conscientização a respeito da coleta dos resíduos sólidos na construção civil. Revista Geociências-UNGSer, v.19, n.1, pp.15-21, 2020.

GOUVEIA, N. Resíduos sólidos urbanos: impactos socioambientais e perspectiva de manejo sustentável com inclusão social. Ciênc. saúde coletiva, Rio de Janeiro, v. 17, n. 6, p. 1503-1510, June 2012. 
MARCOTTO, H. A; TESSARO, A. A.; TESSARO, A. B. Avaliação do conhecimento de alunos do ciclo básico sobre reciclagem. Revista Brasileira de Educação Ambiental, v. 9, n. 2, p. 451-460, 2014.

MESQUITA, A. S. G.. Análise da geração de resíduos sólidos da construção civil em Teresina, Piauí. HOLOS, [S.I.], v. 2, p. 58-65, maio 2012.

PASCHOALIN FILHO, J. A.; GRAUDENZ, G. S. Destinação irregular de resíduos de construção e demolição (RCD) e seus impactos na saúde coletiva. Revista de Gestão Social e Ambiental, v. 6, n. 1, p. 127-142, 2012.

SCHNEIDER, D. M.; PHILIPPI JR, A.. Gestão pública de resíduos da construção civil no município de São Paulo. Ambiente Construído, v. 4, n. 4, p. 21-32, 2004.

SILVA, M. P. et al. A responsabilidade do engenheiro civil perante as legislações de resíduos da construção civil. Revista Panorâmica online, v. 2, 2019.

SILVA, V.G. Avaliação da sustentabilidade de edifícios de escritórios brasileiros: diretrizes e base metodológica. 2003.210f. Tese (Doutorado em Engenharia). Escola Politécnica, Universidade de São Paulo, São Paulo, 2003. Disponível em: $<$ http://www.fec.unicamp.br/ vangomes/Download Tese/Capa.pdf >. Acesso em 30 de jan de 2021.

SILVA, V. A.; FERNANDES, A. L. T.. Cenário do gerenciamento dos resíduos da construção e demolição (RCD) em Uberaba-MG. Soc. nat., Uberlândia, v. 24, n. 2, p. 333-344, Aug. 2012.

SOUSA, A. A. P. et al. A responsabilidade ambiental na formação do engenheiro civil. Maranhão: Revista do CEDS, v. 1, n. 3, 2015.

SOUZA, B. A. et al. Análise dos indicadores PIB nacional e PIB da indústria da construção civil. RDE-Revista de Desenvolvimento Econômico, v. 17, n. 31, 2015.

SOUZA, P. A. B. F.; MARQUES JUNIOR, S. A importância da Educação Ambiental na formação de profissionais de engenharia relacionados ao setor de transportes urbanos. In: Congresso Brasileiro de Educação em Engenharia. PUC-RS, Porto Alegre, 2001. Anais eletrônicos...PUCRS - Porto Alegre/RS, 2001.

Disponível em:<http://www.abenge.org.br/cobenge/arquivos/18/trabalhos/EMA027.pdf>. Acesso em 29 de jan de 2021.

TAUMATURGO, A. C.; DE ALENCAR, D.; BRITO JÚNIOR, J.; DA SILVA, W. ÍCARO; DE OLIVEIRA, S. R. Implementation of a waste management plan in the construction site in Manaus case study. ITEGAM-JETIA, v. 5, n. 20, p. 4550, 2 dez. 2019. 
TAVARES, J. C., DE LIMA, T. N., DE OLIVEIRA, L. M., ALVES, D. R., SILVA, J. D. J. Análise quantitativa dos resíduos de construção e demolição (RCD) em uma cidade de pequeno porte. In: $2^{\circ}$ Congresso Sul-Americano de Resíduos e Sustentabilidade. Foz do Iguaçu,2019. Anais eletrônicos... Foz do Iguaçu,2019 Disponível em:< http://www.ibeas.org.br/conresol/conresol2019/VII-069.pdf>. Acesso em 29 de jan de 2021

ULSEN, C. et al. Composição química de agregados mistos de resíduos de construção e demolição do Estado de São Paulo. Rem: Rev. Esc. Minas, Ouro Preto, v. 63, n. 2, p. 339-346, June 2010.

VECHI, N. R. G., GALLARDO, A. L. C. F., \& TEIXEIRA, C. E. (2016). Aspectos ambientais do setor da construção civil: uma contribuição para a adoção de sistema de gestão ambiental pelas pequenas e médias empresas de prestação de serviços. Sistemas \& Gestão, v. 11, n. 1, p. 17-30. 